\title{
Calcium Carbonate Particle Formation through Precipitation in a Stagnant Bubble and a Bubble Column Reactor
}

\author{
Christopher. J. Grimes, * Thomas Hardcastle, Mohamed S. Manga,* Tariq Mahmud, and David W. York
}

Cite This: Cryst. Growth Des. 2020, 20, 5572-5582

Read Online

ABSTRACT: The precipitation of $\mathrm{CaCO}_{3}$ via $\mathrm{CO}_{2}$ bubbling using well-defined membranes was used in this study to produce particles of a variety of structures. Studies into the mechanisms of particle formation via this method are limited and are mainly specific to hollow structures. Using a range of analytical techniques, particles produced with a stagnant bubble and in bubbling systems (crossflow and vertical flow) were investigated. The stagnant bubble work concluded that the particles are produced both in bulk but also at the gas/liquid interface which then fall down and

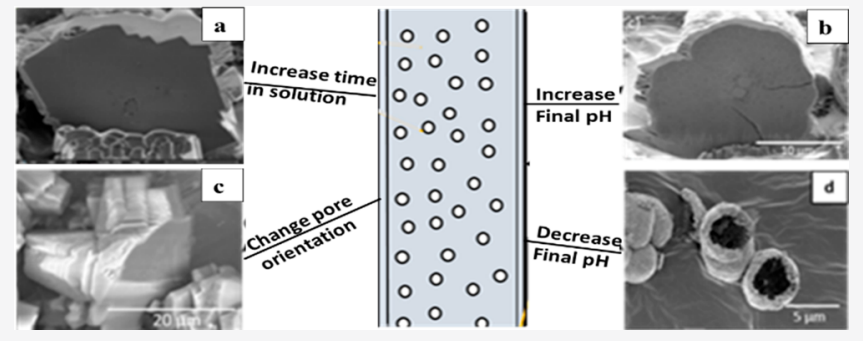
collect at the base of the bubble, whereas in a dynamic system the bubble wake has an important role in precipitation of such particles. Precipitation occurs as the solution $\mathrm{pH}$ drops due to $\mathrm{CO}_{2}$ bubbling (acidic gas), and these particles are initially comprised of a solid core. As the $\mathrm{pH}$ drops further, these particles transform to ones with a hollow core and the $\mathrm{pH}$ plays an important role in controlling the particle shell thickness. Allowing the particles to age in solution allows for transformation of such particles from vaterite to calcite. Finally, the particle structure can also be altered by changing the bubbling set up as having a recirculation loop leading to the formation of particles exhibiting a stacked cube.

\section{INTRODUCTION}

The versatility and abundance of calcium carbonate $\left(\mathrm{CaCO}_{3}\right)$ has led to it becoming an essential formulation component within the pharmaceutical, filler, paper, concrete, plastic, dye, and pigment industries. ${ }^{1-3}$ Traditionally $\mathrm{CaCO}_{3}$ particles have been produced by crushing and grinding limestone or marble to produce ground calcium carbonate (GCC). This is then sieved to achieve the required size (typically in the micron size range). This produces oversized particles that need to be additionally ground, while the fines are usually disposed of or need additional processing. This method of producing of $\mathrm{CaCO}_{3}$ is inefficient and is also very energy-intensive (requires $0.817 \mathrm{kWh} / \mathrm{kg}$ to obtain particles of $7.7 \mu \mathrm{m}$ from a feed particle size of $180-210 \mu \mathrm{m}){ }^{4}$

An alternative method of producing micron-sized $\mathrm{CaCO}_{3}$ is through the precipitation of the particles in solution referred to as precipitated calcium carbonate (PCC). The particle purity, yield, and particle characteristics generated via this method are generally seen as superior to those of GCC. ${ }^{3,5}$ Two main methods are employed to produce PCC particles: (i) a liquidliquid system using a direct reaction between $\mathrm{Ca}^{2+}$ and $\mathrm{CO}_{3}{ }^{2-6}$ and (ii) a gas-liquid system which involves the bubbling of $\mathrm{CO}_{2}$ gas into a solution containing $\mathrm{Ca}^{2+}$ ions such as $\mathrm{Ca}(\mathrm{OH})_{2}{ }^{7-12}$ or $\mathrm{CaCl}_{2}$ in the presence of ammonium hydroxide/amine solutions. ${ }^{13-15}$

The focus of this paper is on the utilization of the latter method using $\mathrm{CaCl}_{2}$ as the calcium source, as $\mathrm{Ca}(\mathrm{OH})_{2}$ is sparingly soluble in water $\left(1.6 \mathrm{~g} / \mathrm{L}\right.$ at $\left.20{ }^{\circ} \mathrm{C}\right)$ which can lead to excessive carbonation times $(\sim 100 \mathrm{~min})$ without the use of additional additives. ${ }^{16}$ In addition, to increased product yield, comminution may be needed either simultaneously or separately to the carbonation stage, to expose the unreacted calcium hydroxide surface. In contrast, $\mathrm{CaCl}_{2}$ is highly soluble and separation of the precipitated product is straightforward.

The overall reaction that takes place when using $\mathrm{CaCl}_{2}$ can be expressed as

$$
\begin{gathered}
\mathrm{CaCl}_{2(\mathrm{aq})}+2 \mathrm{NH}_{4} \mathrm{OH}_{(\mathrm{aq})}+\mathrm{CO}_{2} \\
\rightarrow \mathrm{CaCO}_{3(\mathrm{~s})}+2 \mathrm{NH}_{4} \mathrm{Cl}_{(\mathrm{aq})}
\end{gathered}
$$

In this reaction, ammonium hydroxide (alternatively amines can also be used) serves two purposes; first to promote the absorption of $\mathrm{CO}_{2}$ into solution by forming ammonium carbonate (R.2) and second to serve as an alkalinity source. ${ }^{17}$

$$
\begin{aligned}
2 \mathrm{NH}_{4} \mathrm{OH}+\mathrm{CO}_{2} & \leftrightarrow\left(\mathrm{NH}_{4}\right)_{2} \mathrm{CO}_{3}+\mathrm{H}_{2} \mathrm{O} \Delta H \\
& =-110 \mathrm{~kJ} / \mathrm{mol}
\end{aligned}
$$

The calcium chloride then reacts with the ammonium carbonate to form calcium carbonate and ammonium chloride

Received: May 29, 2020

Revised: July 9, 2020

Published: July 9, 2020 


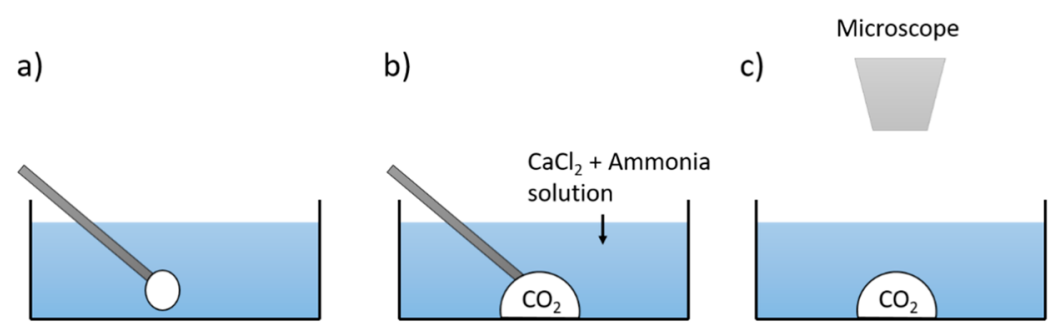

Figure 1. Setup of static hemispherical bubble experiments showing (a) bubble generation at the tip of a capillary within a $\mathrm{CaCl}_{2}$ and $\mathrm{NH}_{4} \mathrm{OH}$ solution, (b) attachment of bubble to base of dish, and (c) monitoring of particle formation using microscopy.
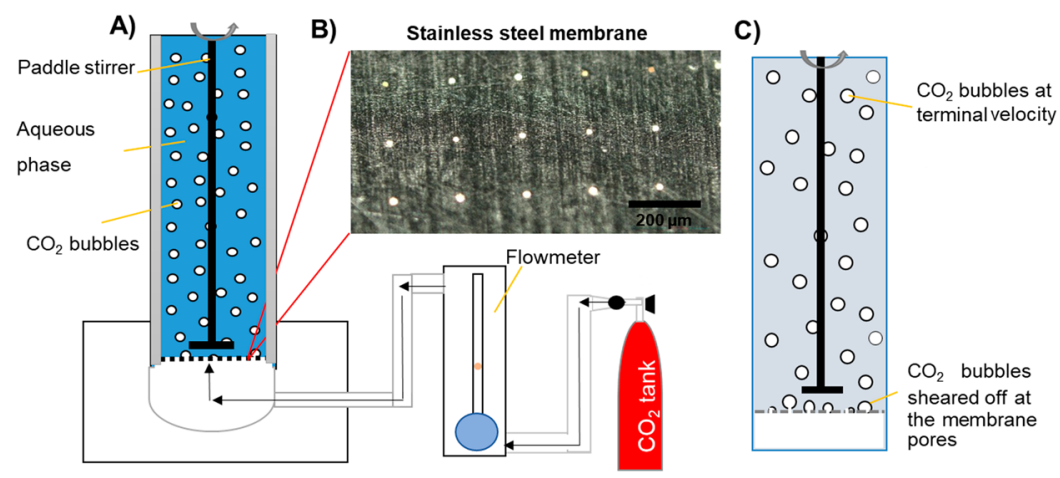

Figure 2. (a) Schematic illustration of the stirred cell membrane rig setup to precipitate calcium carbonate particles by carbonation of $\mathrm{CaCl}_{2}$ and $\mathrm{NH}_{4} \mathrm{OH}$ in the aqueous phase, (b) optical micrograph of the $20 \mu \mathrm{m}$ hydrophilic stainless steel disk membrane used in this study, and (c) formation and detachment of $\mathrm{CO}_{2}$ bubbles expressed through the porous membrane into the continuous phase via shear generated by the paddle stirrer or spontaneous detachment in the absence of shear.

(R.3), which react with water to form ammonium hydroxide in alkaline conditions (R.4).

$$
\begin{aligned}
& \left(\mathrm{NH}_{4}\right)_{2} \mathrm{CO}_{3}+\mathrm{CaCl}_{2} \leftrightarrow \mathrm{CaCO}_{3(\mathrm{~s})}+2 \mathrm{NH}_{4} \mathrm{Cl} \\
& \Delta \mathrm{H}=14-19 \mathrm{~kJ} / \mathrm{mol} \\
& \mathrm{NH}_{4} \mathrm{Cl}+\mathrm{H}_{2} \mathrm{O} \leftrightarrow \mathrm{NH}_{4} \mathrm{OH}+\mathrm{HCl}
\end{aligned}
$$

The mechanism of how such particles form using $\mathrm{CO}_{2}$ gas has been the subject of numerous studies. Tsutsumi et al. ${ }^{18}$ found when injecting single bubbles into a calcium hydroxide solution, that primary nucleation occurred within the vicinity of the bubble, which then underwent secondary nucleation and agglomeration in the bubble wake region due to attrition of growing crystals caused by the vorticial motion. Hadiko et al. ${ }^{13}$ produced hollow precipitated particles when using a calcium chloride salt in the presence of ammonium hydroxide. Initially, this was thought to arise due to homogeneous nucleation of vaterite nanoparticles in the bulk, which would then adhere to the surface of the bubble. As the interface became saturated with nanoparticles, agglomeration occurred to form the hollow sphere. This was also alluded to by Peng et al. ${ }^{19}$ for the formation of hollow $\mathrm{ZnSe}$ spheres. This proposed mechanism $^{13}$ was later revised on the basis that homogeneous nucleation followed by nanoparticle adsorption onto the bubble surface did not adequately explain the formation, due to similar surface charges, i.e., electrostatic repulsion. ${ }^{20}$ Instead, these hollow particles formed due to (i) heterogeneous nucleation occurring at the bubble surface that aggregated to form an initial shell (matching a similar model proposed by Aquilano et $\mathrm{al}^{21}$ ) and (ii) further reaction between the $\mathrm{Ca}^{2+}$ and $\mathrm{CO}_{3}{ }^{2-}$ aiding crystal growth of the outer shell. ${ }^{20}$

In summary, there are a wide range of particle shapes, structures, and sizes that have been made using a reactive gas bubble route, yet the consensus on their formation mechanisms is limited and contradictory. Attempts at modeling the system have also been few and limited to the specific conditions within the experiments, thus not providing a synthesis of the whole body of work from other publications. While not the aim of this work, it is known that several easily changeable process variables can change the size and morphology of calcium carbonate particles. The impact in literature does have severely conflicting findings though these factors are agreed upon. The first is temperature, which changes both the size and the morphology of the particles. It is agreed upon that the morphology shifts away from calcite as temperature increases, but the impact on size is conflicting. ${ }^{16,22,23}$ The rest of the variables that influence particles characteristics are gas flow rate, concentration of calcium source, gas composition, the absorbent/additive used, absorbent concentration (if used), and $\mathrm{pH}$.

This work, therefore, seeks to build toward an understanding on which if any of the mechanisms are applicable to the processes. The observations and results will be used to shape an understanding on how the particles are formed and if any current formation mechanisms are represented by this. This will be done by first studying the reaction and the subsequent particles using a stagnant bubble. The observations will then be compared to a bubbling system (a continuous flow of gas bubbles into a liquid phase) where numerous bubbles are created using a well-defined porous membrane under different flow conditions.

\section{MATERIALS AND METHODOLOGY}

Materials. Calcium chloride hexahydrate $\left(\mathrm{CaCl}_{2}\right.$, purity $\geq 98 \%$, Sigma-Aldrich), ammonium hydroxide $\left(\mathrm{NH}_{4} \mathrm{OH}\right.$ with $\mathrm{NH}_{3}$ basis = $28 \%$, Sigma-Aldrich), acetic acid (reagent grade, Sigma-Aldrich), ethanol (reagent grade, VWR), and carbon dioxide (BOC gases) were 


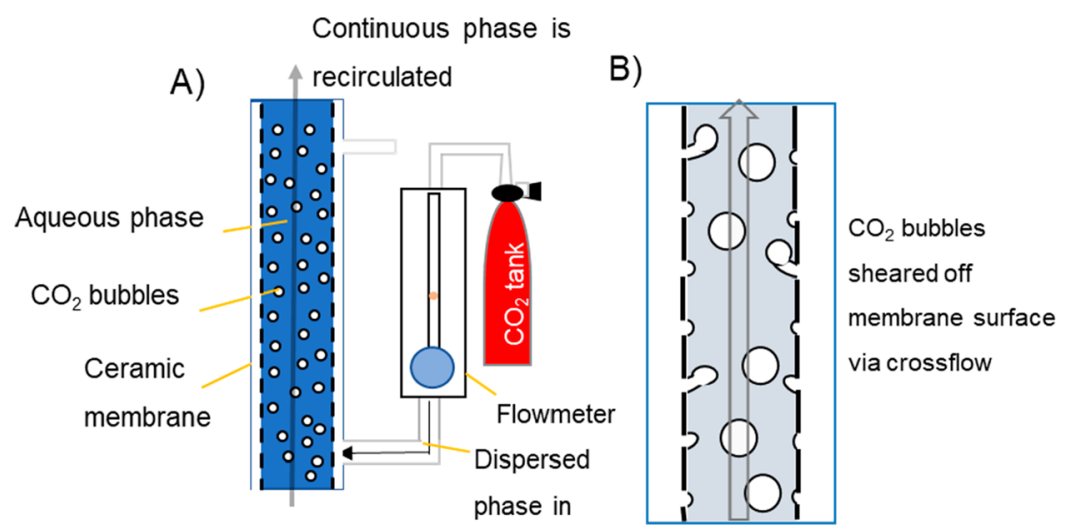

Figure 3. (a) Schematic illustration of the crossflow membrane set up to produce precipitated calcium carbonate particles. The $\mathrm{CO}_{2}$ is pressurized and expressed through the porous ceramic membrane into the continuous phase containing $\mathrm{CaCl}_{2}$ and ammonium hydroxide. (b) Detachment of $\mathrm{CO}_{2}$ bubbles in a crossflow membrane approach.
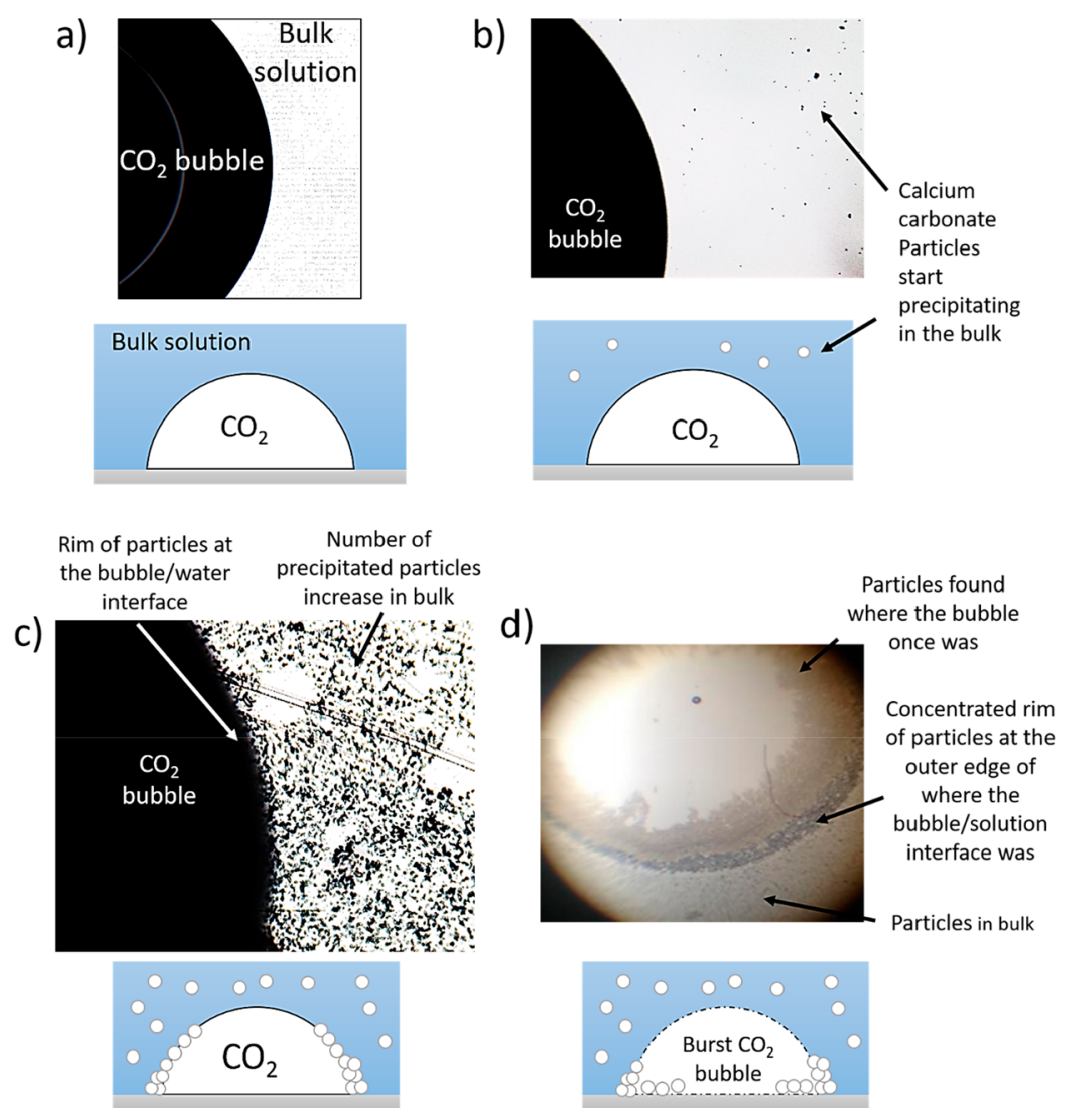

Figure 4. Optical micrographs and the proposed schematic of precipitation mechanism of (a) bubble is attached to the bottom of a plastic Petri dish in a solution of ammonia and calcium chloride at $\mathrm{pH} 11,(\mathrm{~b})$ presence of precipitated particles forming in the bulk indicating partial solubility of $\mathrm{CO}_{2}$ into solution to form precipitates, (c) increase in the number of particles precipitating within the bulk and formation of a rim of particles at the bubble/solution interface, $(\mathrm{d})$ area previously occupied by a bubble that had burst (shown as a dash line in the schematic) showing a high density of particle deposition at the rim and deposition inward as well particles within the bulk. If a highly stable bubble is formed this may lead to a complete particle shell with a hollow core upon reaction completion.

used as received. Distilled water was used in the preparation of all solutions. The mass of the precipitate was gathered using the solid powder on the filter paper while the yield is defined as the percent of calcium ions consumed in the solution.

Methodology. At least three repetitions occurred for each condition tested.

Single Static Bubble-Hemispherical Approach. An aqueous solution of $\mathrm{CaCl}_{2}(0.01 \mathrm{M})$ was adjusted to $\mathrm{pH} 11$ by the addition of $\mathrm{NH}_{4} \mathrm{OH}$ and then transferred into a clear Perspex petri-dish. A glass capillary connected to a flow valve was used to deposit $\mathrm{CO}_{2}$ bubbles $(0.1-1 \mathrm{~mm})$ into this solution such that the bubbles adhered to the base of the vessel as shown in Figure 1. These bubbles were then observed using a Celestron Digital Microscope to monitor the precipitation of calcium carbonate particles. This was conducted at room temperature.

Bubble Reactor-Semibatch Cell Membrane Reactor. A cell membrane reactor rig (LDC-1 by Micropore Technologies Ltd., U.K.) equipped with a $20 \mu \mathrm{m}$ hydrophilic stainless steel disc membrane (pitch $-200 \mu \mathrm{m}$ ) was used to bubble $\mathrm{CO}_{2}$ into an aqueous phase containing $2.77 \mathrm{M} \mathrm{CaCl}_{2}$ and $0.29 \mathrm{M} \mathrm{NH} \mathrm{NH}_{4} \mathrm{OH}$ 
solution (Figure 2). Prior to use, the membrane was extensively cleaned using acetic acid, ethanol, and distilled water. Once set up, the cell was filled with a solution containing $90 \mathrm{~mL}$ of $\mathrm{CaCl}_{2}$ solution and $10 \mathrm{~mL}$ of ammonium hydroxide solution. The $\mathrm{CO}_{2}$ was then injected into the system through the membrane to produce gas bubbles in solution at flow rates between 0.1 and $1.0 \mathrm{~L} / \mathrm{min}$ controlled using a flowmeter valve. The bubbles detach spontaneously (in the absence of a paddle stirrer i.e. dead-end mode) or via shear caused by the paddle stirrer operated at $300 \mathrm{rpm}$ (based on the value used by Hadiko et al. ${ }^{13}$ ). The reaction would be deemed complete upon the formation of a white precipitate causing the colorless solution to become cloudy coinciding with a solution $\mathrm{pH} \approx 8$. The reaction was conducted at room temperature and the precipitated particles were collected via filtration with a distilled water step and allowed to dry in a convection oven at $50{ }^{\circ} \mathrm{C}$ overnight for particle characterization. In addition, a ceramic membrane with a pore size of 200 and $500 \mathrm{~nm}$ (placed into a tall $500 \mathrm{~mL}$ beaker) was also used to investigate the influence of pore size on the particle size. The solution in this case was stirred using a magnetic stir bar at $300 \mathrm{rpm}$. The $500 \mathrm{~nm}$ porous membrane (placed into a tall $500 \mathrm{~mL}$ beaker) was also used to investigate the influence of $\mathrm{pH}$ conditions by use of a $\mathrm{pH}$ probe. This is because in the stirred cell system, once the paddle stirrer is attached, a $\mathrm{pH}$ probe cannot be inserted to monitor $\mathrm{pH}$ changes in solution. Again, the solution was stirred using a magnetic stir bar operated at $300 \mathrm{rpm}$.

Bubble Reactor-Continuous Crossflow with Recycle Reactor. In the cross-flow membrane method, a tubular multichannel ceramic membrane (Fairey Technical Ceramics Ltd. U.K.) with a pore size of $0.2 \mu \mathrm{m}$ is used which is housed within a cylindrical stainless steel module. This allows separate shell and tube paths and further details related to the rig can be found elsewhere. ${ }^{24,25}$ The $\mathrm{CO}_{2}$ gas is pressurized into the annulus shell path $(1 \mathrm{bar})$ and the aqueous phase is recirculated in the tube via a centrifugal pump. The gas permeates the membrane pores under pressure and forms gas bubbles on the inner surface of the membrane tube in the flowing continuous phase. The bubbles are detached by a shear force caused by the cross-flowing continuous phase (Figure 3). The pressure difference (transmembrane pressure) between two phases in the membrane module used here was $\sim 0.05 \mathrm{MPa}$. The circulation (or cross-flow) velocity of the continuous phase in the membrane channel was $1.75 \mathrm{~m} / \mathrm{s}$. The 3 $\mathrm{L}$ continuous phase consisted of $2.7 \mathrm{M} \mathrm{CaCl}_{2}(2.7 \mathrm{~L})$ and $0.21 \mathrm{M}$ $\mathrm{NH}_{4} \mathrm{OH}(0.3 \mathrm{~L})$. The reaction was terminated once the appearance of the continuous phase becomes turbid and has a $\mathrm{pH}$ value equal to $\sim 8$. The precipitation reaction was done at room temperature.

Particle Characterization. Laser diffraction (Malvern Mastersizer 2000E equipped with a small volume Hydro 2000SM sample dispersion unit) and scanning electron microscopy (SEM) and was employed to size the particles. Images obtained via SEM (Hitachi TM3030+) were analyzed using Image J software (developed by the National Institutes of Health and the Laboratory for Optical and Computational Instrumentation) to obtain particle size $\left(d_{50}\right)$ and size distribution information with both the span $\left(\left(d_{90}-d_{10}\right) / d_{50}\right)$ and the particle distribution curves being presented. Particle surface characterization and internal structures were characterized with the following scanning electron microscopes:

- FEI Helios G4 CX DualBeam-High resolution monochromated equipped with a focused ion beam which mills the particle and images it in situ.

- Carl Zeiss EVO MA15: variable pressure W SEM.

\section{RESULTS AND DISCUSSION}

Stagnant Bubble Approach. To probe the formation mechanism, single static bubble experiments were performed where a single hemispherical $\mathrm{CO}_{2}$ bubble (adhered to the base of a Petri-dish) was placed in a $\mathrm{CaCl}_{2}$ and $\mathrm{NH}_{4} \mathrm{OH}$ solution at $\mathrm{pH} 11$ and observed using optical microscopy (Figure 4). A stationary bubble in liquid depicts a model scenario to learn further about how such particles precipitate and form via imaging (Figure 4a). Initially, a small number of particles begin precipitating in the bulk (Figure $4 \mathrm{~b}$ ), which increase in number over time (Figure 4c). Additionally in Figure 4c, there appears to be a large concentration of precipitates residing at the bubble/liquid interface (rim of particles), suggesting that the surface of the bubble may also act as site for heterogeneous nucleation to occur. Unfortunately due to slow evaporation of the solution, the stagnant bubble burst. Where the bubble had been (Figure 4d), a highly concentrated rim of particles can be seen at the outer edge (interface between bubble and solution), with a decreasing concentration of particles deposited inward. It is envisaged that due to the large bubble size, a complete particle shell around a bubble core was unable to develop and instead the particles rolled down the bubble surface due to gravity and deposited at the base. Had the bubble remained, these particles would begin to assemble and structure to form a complete particle shell and produce a hollow core. With the bubble bursting, there was no structure to hold the partially formed shell and hence it fell inward.

Particles were also observed in the bulk away from the bubble surface, which can be seen in Figure $4 \mathrm{a}$ indicating that homogeneous nucleation also took place. The bulk phase contains $\mathrm{NH}_{4} \mathrm{OH}$, which promotes the absorption and solubilization of $\mathrm{CO}_{2}$ into solution. Thus, both heterogeneous and homogeneous nucleation occurs leading to the formation of the precipitated particles as depicted in Figure $4 \mathrm{~b}$. These particles then sediment due to the density difference over time. Taking the primary particle size of $\sim 120 \mathrm{~nm}$ (based on SEM imaging, S1 in the Supporting Information), it would take over 3 days for the particles to settle from the top to the bottom of the bubble (when the bubble diameter is $1 \mathrm{~mm}$ ). The formation of particles on the surface of a static bubble as well as in the bulk solution indicates a complex particle formation mechanism. Further work is needed to understand the influence of interfacial area and ionic concentration of the reactants on how the particles precipitate and form both at the interface and in the bulk, but it is believed particles form in the bulk due to spontaneous agglomeration of nanoparticles.

Bubble Reactor System. Traditional air diffusers such as porous ceramic are composed of pore sizes with a wide pore size distribution. This can lead to poor control of the bubble size distribution generated from such pores which leads to differing bubble residence times in solution impacting the mass transfer rate. To exert control over the size of bubbles produced in this study, a laser drilled stainless steel membrane with a pore size of $20 \mu \mathrm{m}$ housed within a stirred cell was used. Previous studies have shown controlled production of emulsion droplets as well as particulates with the same device. $^{26-28}$ The droplet/bubble size is usually within a size range of 2 to 5 times the pore diameter (by controlling the shear rate across the membrane surface as well as the time taken to generate new interfacial area). ${ }^{29}$ In traditional bubble columns, the gas bubble diameter is also highly dependent on the pore diameter and numerous correlations in literature have been developed to predict the gas bubble size..$^{30-33}$

In this study, initial work was conducted in the absence of shear to prepare bubbles with a size similar to that achieved in the static bubble experiments. This was characterized by measuring the bubble size generated using a high speed camera (Fastcam SA5, Photron) (examples of which can be found in the Supporting Information, S2) and analyzed using an image processing software, ImageJ. By increasing the gas flow rate, the resulting bubbles also increased in size (Table 1) as they grew to a larger size prior to spontaneous detachment off the 
Table 1. Summary of the Predicted Bubble Size, Experimental Bubble Size (Number Mean, $D[1,0]$ ), Reaction Time, Mean Particle Size, and the Associated Standard Deviation for Precipitated Calcium Carbonate Particles Produced in the LDC-1 Reactor at Various Flow Rates $^{a}$

\begin{tabular}{|c|c|c|c|c|c|}
\hline $\begin{array}{l}\text { gas flow } \\
\text { rate } \\
(\mathrm{L} / \mathrm{min})\end{array}$ & $\begin{array}{l}\text { predicted } \\
\text { bubble } \\
\text { size } \\
(\mathrm{mm})\end{array}$ & $\begin{array}{l}\text { experimental } \\
\text { bubble size } \\
\text { (number mean, } \\
D[1,0])(\mathrm{mm})\end{array}$ & $\begin{array}{l}\text { reaction } \\
\text { time }(s)\end{array}$ & $\begin{array}{l}\text { mean } \\
\text { particle } \\
\text { size, } d_{50} \\
(\mu \mathrm{m})\end{array}$ & $\begin{array}{l}\text { standard } \\
\text { deviation } \\
(\mu \mathrm{m})\end{array}$ \\
\hline 0.1 & 0.92 & $1.04 \pm 0.1$ & 140 & 12.7 & 9.8 \\
\hline 0.2 & 0.93 & $1.06 \pm 0.1$ & 110 & 10.1 & 7.4 \\
\hline 0.5 & 0.94 & $1.13 \pm 0.1$ & 47 & 16.6 & 11.6 \\
\hline 0.8 & 0.94 & $1.18 \pm 0.1$ & 34 & 7.5 & 6.7 \\
\hline 1 & 0.94 & $1.28 \pm 0.1$ & 23 & 9.8 & 8.8 \\
\hline
\end{tabular}

${ }^{a}$ Pure $\mathrm{CO}_{2(\mathrm{~g})}$ was bubbled into a reaction solution of $2.77 \mathrm{M} \mathrm{CaCl}_{2}$ and $0.29 \mathrm{M} \mathrm{NH}_{4} \mathrm{OH}$ at room temperature and in the absence of shear.

membrane surface but no coalescence was observed as the particles rose. The table also includes the theoretic gas bubble size as calculated using the correlation developed by Miller ${ }^{1}$

$$
d_{\mathrm{b}}=\left[\frac{6 \gamma d_{\mathrm{p}}}{g\left(\rho_{1}-\rho_{\mathrm{g}}\right)}\right]^{1 / 3}
$$

where $d_{\mathrm{b}}$ is the bubble diameter, $\gamma$ is the surface tension, $d_{\mathrm{p}}$ is the pore diameter, $g$ is the gravitational constant, $\rho_{1}$ and $\rho_{\mathrm{g}}$ are the liquid and gas densities, respectively.

The number of bubbles produced also increases with gas flow rate as the percent of pores that become active in droplet generation also increases. This has an influence on the reaction times (determined by change in solution turbidity from transparent to a milky white solution by visual observation) as the overall interfacial area is dramatically increased. This can be seen in Table 1 where the reaction time goes from $140 \mathrm{~s}$ at $0.1 \mathrm{~L} / \mathrm{min}$ to $23 \mathrm{~s}$ at $1 \mathrm{~L} / \mathrm{min}$. The time taken for precipitates to form is determined by the mass transfer rate of the carbonate ions crossing the liquid film surrounding the bubble into the bulk solution to finally produce the calcium carbonate particles. This reaction scheme in which the mass transfer was dictating precipitation time was validated through the addition of a solution of $\left(\mathrm{NH}_{4}\right)_{2} \mathrm{CO}_{3(\mathrm{aq})}$ to $\mathrm{CaCl}_{2(\mathrm{aq})}$ which formed a white precipitate instantaneously. By tracking $\sim 100$ bubbles and their duration in solution (in the absence of shear at the membrane surface), an average bubble residence time can be calculated. This then enables the calculation of the mass transfer rate, $\dot{m}$, across the interface for the chemisorption of $\mathrm{CO}_{2}$ from bubbles into solution using the expression derived by Hlawitschka et al. ${ }^{34}$ as summarized in Table 2 .

The mass transfer rate can be depicted by

$$
\dot{m}=\frac{A_{\text {bubble }}}{V_{\text {bubble }} d} E \alpha_{g} D S h \rho_{1}\left(H \frac{\rho_{\mathrm{g}}}{\rho_{1}}-Y_{1}\right)
$$

where $A_{\text {bubble }}$ is the surface area of bubble, $V_{\text {bubble }}$ is bubble volume, $d$ is diameter, $E$ is an enhancement factor (equates to unity up to a $\mathrm{pH}$ value of 10 in water), $\alpha_{\mathrm{g}}$ is the specific interfacial area, $D$ is the diffusion coefficient, $S h$ is Sherwood's number $(S h=2+0.6415 \sqrt{R e S c}), \rho$ is density, $H$ is Henry's constant, and $Y_{1}$ is the chemical species concentration in liquid. $^{34}$ The Reynolds number, $R e$, and the Arrhenius number, $A r$, were calculated using eqs 3 and 4 . The Schmidt number,
Table 2. Influence of Gas Flow Rate on Bubble Residence Time which Affects the Mass Transfer Rate for the Chemisorption of $\mathrm{CO}_{2}$ into Solution ${ }^{a}$

$\begin{array}{ccccc}\begin{array}{c}\text { gas flow } \\ \text { rate } \\ (\mathrm{L} / \mathrm{min})\end{array} & \begin{array}{c}\text { experimental bubble } \\ \text { size }(\text { number mean, } \\ D[1,0])(\mathrm{mm})\end{array} & \begin{array}{c}\text { mass } \\ \text { mean bubble } \\ \text { residence } \\ \text { time, } r_{\mathrm{t}}(\mathrm{s})\end{array} & \begin{array}{c}\text { gas } \\ \text { transfer } \\ \text { rate, } \dot{m}, \\ \left(\mathrm{~kg} / \mathrm{m}^{3} \mathrm{~s}\right)\end{array} & \begin{array}{c}\text { removed, } \\ f_{\mathrm{g}}\end{array} \\ 0.1 & 1.04 & 0.87 & 0.15 & 0.06 \\ 0.2 & 1.06 & 0.78 & 0.28 & 0.12 \\ 0.5 & 1.13 & 0.68 & 0.6 & 0.23 \\ 0.8 & 1.18 & 0.58 & 0.85 & 0.31 \\ 1 & 1.28 & 0.49 & 0.89 & 0.3\end{array}$

${ }^{a}$ This has a consequence on the fraction of $\mathrm{CO}_{2}$ removed from the bubble during this time period.

Sc, describes the ratio of momentum diffusivity to mass diffusivity $\left(S c=\nu / \mathrm{D}\right.$, where $v$ is the kinematic viscosity). ${ }^{35}$

$$
\begin{aligned}
& R e=\sqrt{27.2^{2}+0.04094 A r}-27.2 \\
& A r=\frac{g L^{3} \rho_{1}\left(\rho-\rho_{1}\right)}{\mu_{1}}
\end{aligned}
$$

This is useful in determining the gas fraction of $\mathrm{CO}_{2}, f_{g}$, that is removed from the gas bubble during its residence time in solution $\left(r_{\mathrm{t}}\right)$;

$$
f_{\mathrm{g}}=\frac{\dot{m} r_{\mathrm{t}} V_{\text {bubble }}}{m_{\text {bubble }}}
$$

Due to the ammonia offering an alternative reaction pathway and acting like a catalyst in many ways, the enhancement factor, $E$, will no longer be 1 and will also be dependent on the gas flow rate. ${ }^{36}$ These values can be found in the Supporting Information (S3) along with the equations used to calculate them.

As shown in Table 2, the mass transfer rate increases as the gas flow rate increases. Although the bubble size increases (decreasing the interfacial area per unit volume) the high gas flow rate produces a great number of bubbles, which means the total interfacial area available for mass transfer is greatly increased. This results in a greater fraction of gas chemisorbed into solution for the precipitation reaction thus influencing the growth characteristics of the particles formed. This occurs through a greater concentration of ammonium carbonate/ bicarbonate forming causing the reaction rates to increase that changes the level of supersaturation as well as the ratio of primary to secondary nucleation.

Interestingly, it was found that the particle size and size distribution was independent of the gas flow rate used (Table 1 and Figure 5a) due to the fluctuations in particle size. Probing the particle size distributions (Figure $5 b$ ) highlights that the proportion of primary particles vs the aggregate structures is small. A scanning electron micrograph of particles prepared at $0.1 \mathrm{~L} / \mathrm{min}$ is presented in Figure $6 \mathrm{a}$ and is representative of particles formed at the other flow rates studied. The predominant structure formed is that of spherical vaterite (with some appearing "cauliflower like") while, cubic calcite crystals can also be seen in the vicinity of the vaterite particles. Closer inspection of these vaterite particles shows that they are secondary particles made up of smaller primary particles fused together (Figure $6 \mathrm{~b}$ ). These smaller particles were measured (using ImageJ) and found to be between 40 to $160 \mathrm{~nm}$. The micrograph also shows the presence of a "cracklike" feature on 
a)

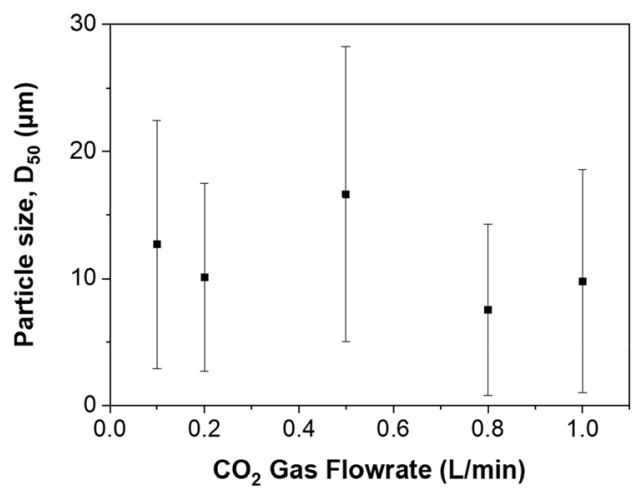

b)

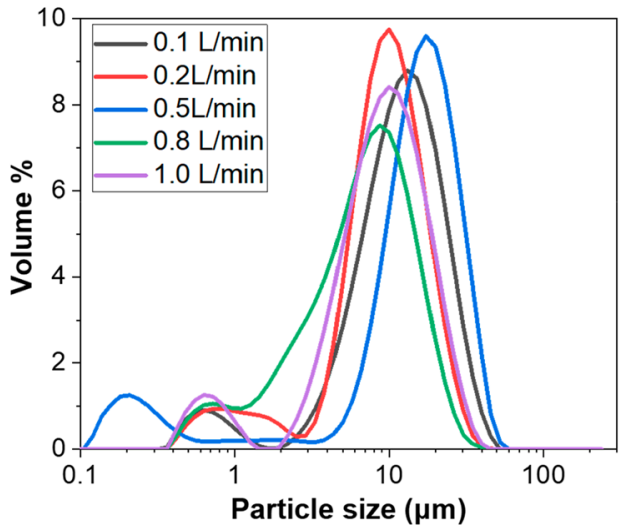

Figure 5. (a) Plot of particle size vs gas flowrate. This graph shows no observable change in particle size $\left(d_{50}\right)$ with gas flow rate (error bars indicate the associated standard deviation), (b) plot of particle size distribution based on volume percent with changing gas flow rate for precipitated calcium carbonate particles produced in the LDC-1 reactor using a $20 \mu \mathrm{m}$ steel membrane using pure $\mathrm{CO}_{2}$ and a $2.78 \mathrm{M}$ $\mathrm{CaCl}_{2}, 0.29 \mathrm{M} \mathrm{NH}_{4} \mathrm{OH}$ solution.

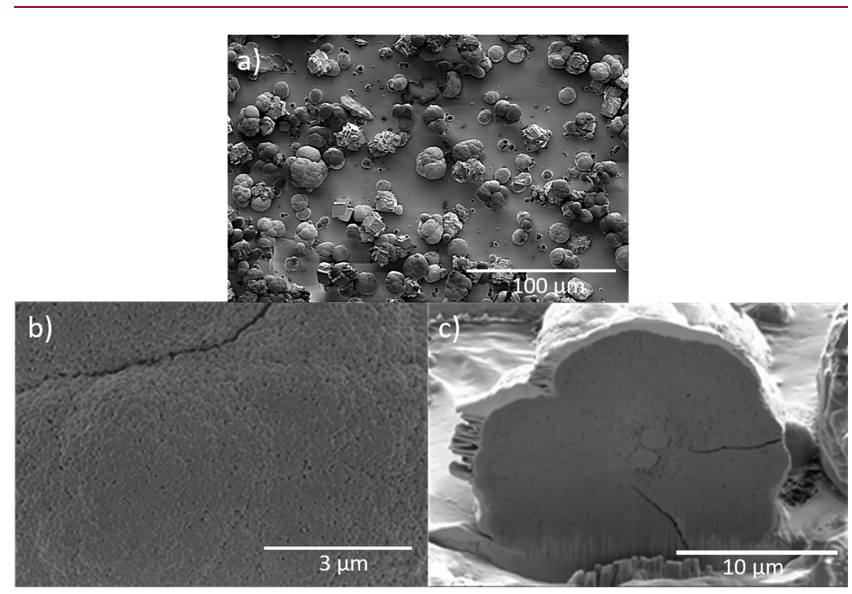

Figure 6. Scanning electron micrographs of calcium carbonate particles prepared using the cell membrane reactor using a gas flow rate of $0.1 \mathrm{~L} / \mathrm{min}$. (A) Representation of the particle size and size distribution and particle morphology (predominantly vaterite), (b) surface of the particle showing the presence of primary particles fused together and the presence of a crack, and (c) a particle milled using a focused ion beam to reveal internal structural information.

the surface of some vaterite particles that also penetrate into the internal structure (Figure 6c). Initially this was thought to be due to sample preparation and drying of the crystal causing mechanical stress upon. However, the width of the crack is $\sim 100 \mathrm{~nm}$ (similar in size to the primary particles) and therefore could also be due to reorganization of a grain boundary as it undergoes a morphological transformation. ${ }^{37,38}$ This may explain the presence of calcite particles in close proximity of the vaterite particles.

The internal structure also shows the appearance of a core (two circles surrounded by a porous ring) indicating two smaller aggregates coming together and subsequent crystal growth occurs radially outward forming a solid particle with inherent porosity. This matches similar observations presented by Costa et al. ${ }^{39}$ It is hypothesized that the bubble wake mechanism proposed by Tsutsumi et al. ${ }^{18}$ may be responsible for the particle formation, as initial nucleation is followed by rapid secondary nucleation and growth and the bubble wake provides an ideal and a saturated environment for this to occur. The rising velocity of the bubble $(11.49 \mathrm{~cm} / \mathrm{s})$ would also dramatically increase the force experienced by the crystals on the surface dragging them to the bottom of the bubble and then into the wake. Meanwhile, flow around the bubble would drag particles present in the bulk into the wake, which would aggregate in the formation of the final particles.

Influence of Bubble Size. To further investigate the influence of bubble size on the particle size and structure, a single channel ceramic membrane with a pore size of $200 \mathrm{~nm}$ was employed. These experiments used a flow rate of $0.1 \mathrm{~L} /$ min to decrease the chance of bubble coalescence (as no bubble coalescence was observed when using high speed imaging when using the $20 \mu \mathrm{m}$ stainless steel membrane) on the membrane surface (as no shear was used to force detachment of the bubbles). The total solution volume again was kept fixed at $100 \mathrm{~mL}$ to allow for comparison. While the bubbles were much smaller than those produced by the $20 \mu \mathrm{m}$ membrane, their actual size was not determined due to difficulties in imaging them. However, it should be noted that they were less than $100 \mu \mathrm{m}$ as they could not be seen with the naked eye. Due to the higher surface area to volume ratio the reaction time was also much faster $(60 \mathrm{~s}$ compared to $140 \mathrm{~s}$ when using the $20 \mu \mathrm{m}$ membrane) indicating a higher diffusion rate of the $\mathrm{CO}_{2}$ into solution.

The resultant particles were found to be spherical vaterite particles with an average particle size of $10 \mu \mathrm{m}$ (Figure 7a);

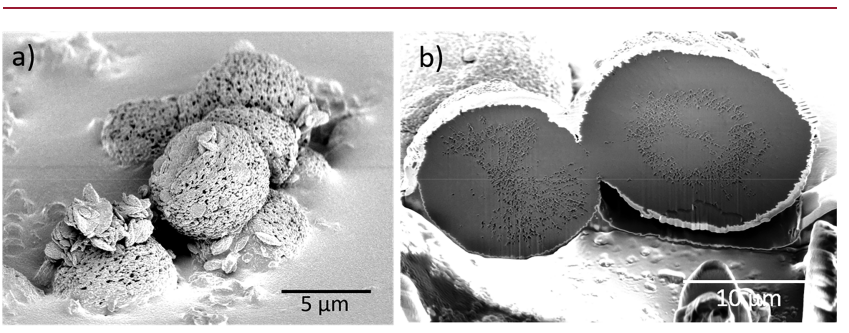

Figure 7. Calcium carbonate particles precipitated using a $0.2 \mu \mathrm{m}$ ceramic membrane at a $\mathrm{CO}_{2}$ flow rate of $0.1 \mathrm{~L} / \mathrm{min}$ in the absence of applied shear showing (a) spherical vaterite particles composed of a "rod" like primary particles and a porous surface structure and (b) particles milled with a focused ion bean revealing a solid internal core and areas of inherent porosity.

however, the surface structure appears different to the vaterite particles presented in Figure 6. The primary particles on the surface that make up the spherical structure appear "rod" or "plate" like with varying particle sizes and aspect ratios. Larger lens like particles can also be seen in the vicinity and appear embedded within the particle surface. It is unclear if these larger particles are due to morphological transformation of the 

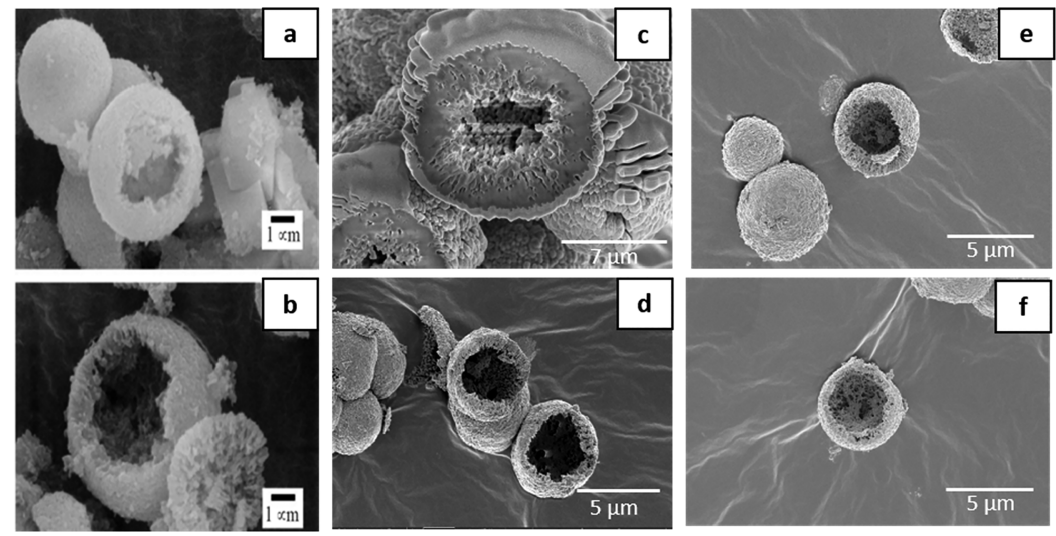

Figure 8. Hollow calcium carbonate particles $(\mathrm{a}-\mathrm{b})$ obtained by Hadiko et al. at an initial $\mathrm{pH}$ of 9.8. (Adapted with permission from ref 13 . Copyright 2005. American Chemical Society). ( $\mathrm{c}-\mathrm{d})$ Hollow calcium carbonate particles after being prepared at $\mathrm{pH} 9.8$ using the stirred cell reactor equipped with a $20 \mu \mathrm{m}$ membrane. A paddle stirrer speed of $300 \mathrm{rpm}$ and a $\mathrm{CO}_{2}$ gas injection rate of $0.1 \mathrm{~L} / \mathrm{min}$ was used. The experiments were carried out at room temperature. $(\mathrm{e}-\mathrm{f})$ at an initial $\mathrm{pH}$ of 11.5. All reactions were allowed to proceed to a final $\mathrm{pH}$ of 6.5 . The dried particles were broken by applying pressure to reveal the hollow structure for imaging.

vaterite structure or due to crystal fragmentation (due to sample preparation). Milling of these particles with a focused ion beam reveals a solid core with regions of inherent porosity (pore size $<100 \mathrm{~nm}$ ) as shown in Figure $7 \mathrm{~b}$. The particle on the right has similar internal characteristics to that seen in Figure 6, but the seed aggregates from which the rest of the particle grows appear much larger. In contrast, the particle on the left has a different porosity pattern and requires further investigation as to the cause of it. One possible theory is that the particle is undergoing internal phase transformation as the porosity patterns match a potential mechanism that has been alluded to by Trushina et $\mathrm{al}^{38}$ As with the $20 \mu \mathrm{m}$ membrane, the resultant particle size when using the $200 \mathrm{~nm}$ membrane are much smaller than the $\mathrm{CO}_{2}$ bubble produced within the system to create them. However, regardless of the membrane pore size used the effective secondary particle size produced is in the range of a few microns. However, one noticeable difference is that when the $200 \mathrm{~nm}$ membrane is used the particles produced show an increase in surface porosity. This may be due to the production of smaller bubbles with a greater surface area to volume ratio and thus increases the diffusion of $\mathrm{CO}_{2}$ into solution to create the particles.

Influence of pH Conditions. In 2005, Hadiko et al. ${ }^{13}$ demonstrated the potential to produce hollow calcium carbonate particles via the bubbling method by carefully controlling both the initial and final $\mathrm{pH}$ of the reaction. Such structures have potential in the pharmaceutical and cosmetic industries. $^{13,20,40-42}$ Hadiko et al. ${ }^{13}$ state that an initial $\mathrm{pH}$ of 9.5-9.8 is required with a final $\mathrm{pH}$ of 6.5 to obtain the desired hollow structure. This initial $\mathrm{pH}$ condition was essential as it slowed down the dissolution rate of $\mathrm{CO}_{2}$ into solution thus providing a bubble template for the formation of a hollow particle. This formation mechanism of these hollow particles was later revised but still stated that an initial $\mathrm{pH}$ of $\sim 9.5$ was needed $^{42}$ as using higher starting $\mathrm{pH}$ values led to calcite being formed. The final $\mathrm{pH}$ of 6.5 is needed for redissolution of primary particles within the secondary particle to form a shell with a hollow core. In the experiments discussed above in this study, all the particles produced had a solid core as the final $\mathrm{pH}$ of the reaction $\approx \mathrm{pH} 8$.

When using the stirred cell reactor, it was found that the final $\mathrm{pH}$ and not the initial $\mathrm{pH}$ dictated the formation of hollow particles. This is illustrated in Figure 8 that shows broken particles to reveal a hollow structure as produced by Hadiko et al. ${ }^{13}$ using an initial $\mathrm{pH}$ of 9.8 (Figure $8 \mathrm{a}$ and $\mathrm{b}$ ), compared to those produced in this study using the same $\mathrm{pH}$ conditions (Figure $8 \mathrm{c}$ and $\mathrm{d}$ ) and when a higher initial $\mathrm{pH}$ of 11.5 is used (Figure $8 \mathrm{e}$ and $\mathrm{f}$ ). The particles were broken by applying pressure in order to image the internal structure to determine if they were solid or hollow.

To probe the particle transformation process from a solid internal structure to a hollow core, a study examining the effect of final solution $\mathrm{pH}$ (8.6 to 6.6) from an initial starting $\mathrm{pH}$ of 11.5 on particle characteristics using a $500 \mathrm{~nm}$ porous ceramic membrane was conducted. This was performed using two techniques ran in parallel. The first was to extract half the precipitated solution at $\mathrm{pH} 8.6$ from the reaction vessel, after which the solution was further bubbled with $\mathrm{CO}_{2}$ until a $\mathrm{pH}$ of 7.6 and 6.6 was obtained. Samples were taken at each of these $\mathrm{pH}$ values for particle size analysis (Table 3). The second

Table 3. Characterization of Mean Particle Size $\left(d_{50}\right)$, Span $\left(\left(d_{90}-d_{10}\right) / d_{50}\right)$, and the Calculated Yields (Based on Calcium and All Absorbed $\mathrm{CO}_{2}$ Reacting) as a Function of Final Solution pH

\begin{tabular}{cccccc} 
mean & $\begin{array}{c}\text { marticle } \\
\text { size, } d_{50} \\
(\mu \mathrm{m})\end{array}$ & span & $\begin{array}{c}\text { calculated } \\
\text { solid } \\
\mathrm{CaCO}_{3} \\
\text { sample }\end{array}$ & $\begin{array}{c}\text { yield based } \\
\text { on calcium } \\
(\%)\end{array}$ & $\begin{array}{c}\text { calculated yield } \\
\text { based on all the } \\
\text { absorbed } \mathrm{CO}_{2} \\
\text { reacting }\end{array}$ \\
pH 8.6 & 6.4 & 2.0 & $0.82 \pm 0.2$ & 3.25 & 70.89 \\
pH 7.6 & 2.8 & 1.2 & $0.80 \pm 0.3$ & 3.24 & 59.10 \\
pH 6.6 & 2.7 & 1.7 & $0.81 \pm 0.2$ & 3.23 & 58.18 \\
pH 6.2 & 2.4 & 1.4 & $0.89 \pm 0.3$ & 3.55 & 58.10 \\
\hline
\end{tabular}

method involved taking the extracted sample at $\mathrm{pH} 8.6$ and was separated into two petri dishes. The solution $\mathrm{pH}$ within the petri dishes was lowered from 8.6 to 7.6 and 6.6, respectively, using carbonic acid while imaging the solutions under an optical microscope.

Reducing the solution $\mathrm{pH}$ within both the petri dishes did not cause any significant changes in the observed solution turbidity (visually) upon the addition of carbonic acid. When the $\mathrm{pH}$ of the solution drops below 7, the basic nature of $\mathrm{CaCO}_{3}$ means that there will be some dissolution occurring to neutralize the acidity. Upon characterization it is seen that the overall particle size decreases with $\mathrm{pH}$, however the mass of 
solid particles extracted from the solution per $100 \mathrm{~mL}$ (Table 3) remains constant. This indicates that dissolution is minimal for this to occur. Additionally, the calculated product yield on the basis of (i) moles of calcium consumed divided by the total moles of calcium ions in solution and (ii) $100 \%$ of the ammonia releases the $\mathrm{CO}_{2}$ captured and this is converted into $\mathrm{CaCO}_{3}$ at each $\mathrm{pH}$ tested are included within the table. Samples were taken and crushed to characterize the internal structure via SEM (Figure 8). The amount of $\mathrm{CO}_{2}$ captured is calculated using the moles of $\mathrm{CO}_{2}$ necessary to produce the $\mathrm{pH}$ drop observed/desired in the system accounting for the buffer effects of the ammonium species present in solution. While using physical data is more desirable, it was not collected at the time. Therefore, this theoretical alternative has been used. It is interesting to note that the yield drops from $70.89 \%$ to $59.10 \%$ between $\mathrm{pH} 8.6-7.6$, but after this point, the reduction in yield is $1 \%$ for a wider $\mathrm{pH}$ change. This trend is likely due to the ability of the ammonium hydroxide to act as a buffer as the $\mathrm{pH}$ becomes increasingly acidic becoming negligible. Therefore, the $\mathrm{pH}$ drops much more quickly causing an increase in the mass of precipitated $\mathrm{CaCO}_{3}$ obtained. The yield data also indicates that some of the $\mathrm{CO}_{2}$ is still bound as an ammonium salt and investigation into the series of reversible reactions could allow for a greater yield to be obtained. Samples were taken and crushed to characterize the internal structure via SEM (Figure 8).

The transformation process from solid to hollow particles (as shown in Figure 9a-d) has been previously alluded to by
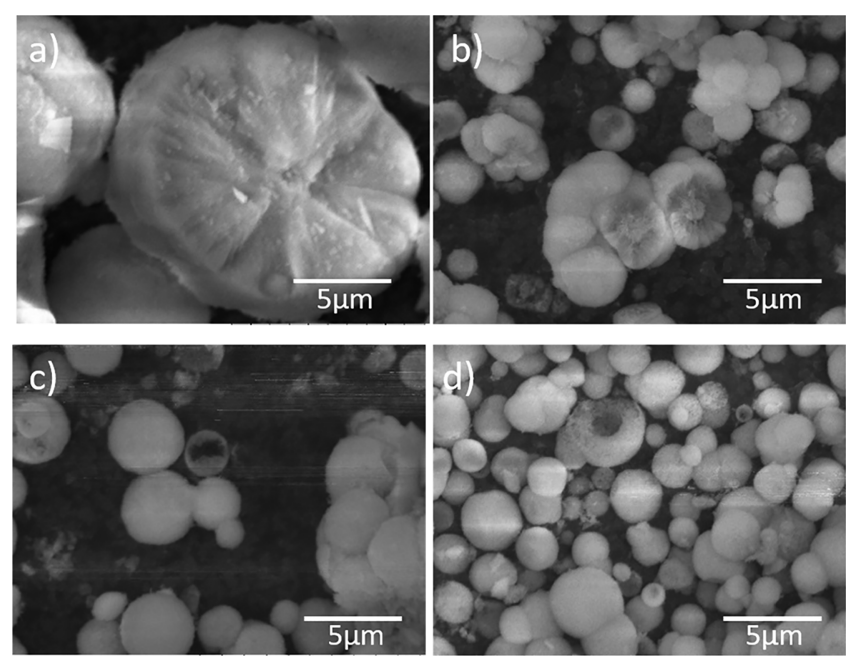

Figure 9. Illustration of how the internal structure of particles changes as the $\mathrm{pH}$ drops from 11.5 to (a) 8.6 then (b) 7.6 , then (c) 6.6, and finally to (d) 6.2 using a $500 \mathrm{~nm}$ porous membrane. A gas flow rate of $0.1 \mathrm{~L} / \mathrm{min}$ was used, and all experiments were conducted at room temperature.

Tomioka et al. ${ }^{42}$ They stated that the newly formed primary particles on the surface of the secondary particles transform into vaterite forming a shell. This reduces the surface energy and leads to a stronger interparticle attractive force between the primary particles leading to a more compact shell. The amorphous particles in the center are high soluble and undergo dissolution and recrystallize as vaterite on the internal surface of the outer shell. This causes a volume contraction due to the water released, leading to the formation of a hollow core.

However, this mechanism alone cannot account for the reduction in particle size with decreasing $\mathrm{pH}$ (Table 3 ). We postulate (as we could not probe it experimentally) that, in addition, the outside shell must also be undergoing dissolution with time as the solution $\mathrm{pH}$ continues to drop. However, this occurs at a much slower rate, due to the lower surface energy and increased stability compared to the highly soluble amorphous calcium carbonate. The loss of material from both sites causes both the hollow structure as well as a reduction in particle size $(\sim 6.4-2.7 \mu \mathrm{m})$ and volume (a reduction of $\sim 90 \%)$. During the expulsion of water from the core associated with the transformation of amorphous to vaterite (deposited on the inner side of the shell), some of the remaining dissolved material may also fill voids within the shell making it more compact as well as forming new primary and secondary particles in the bulk. Since similar product yield is achieved at each $\mathrm{pH}$ studied (Table 3), a reduction in particle size and hollowing of particles indicates that the number of particles produced goes up significantly (assuming a single bubble fully reacts to form the precipitated particles) (Table 4).

Table 4. Illustrates the Number of Particles That Are Produced from One Bubble (taking $1 \mathrm{~mm}$ as a Reference Size and Assuming the Whole Bubble Partakes in the Reaction) for Particles Produced at pH 8.6, 7.6, 6.6, and 6.2

\begin{tabular}{cccc}
$\mathrm{pH}$ & $\begin{array}{c}\text { particle diameter } \\
(\mu \mathrm{m})\end{array}$ & $\begin{array}{c}\text { shell thickness } \\
(\mu \mathrm{m})\end{array}$ & $\begin{array}{c}\text { number of particles per } \\
\text { bubble }\end{array}$ \\
8.6 & 6.4 & 0 & 7079 \\
7.6 & 2.8 & 0 & 84530 \\
6.6 & 2.7 & 0.31 & 307295 \\
6.2 & 2.4 & 0.73 & 201323 \\
\hline
\end{tabular}

Dropping the $\mathrm{pH}$ further (from 6.6 to 6.2) leads to hollow particles with an increased shell thickness increased from 0.31 to $0.74 \mu \mathrm{m}$ (Figure $8 \mathrm{~d}$ and Table 4 ) indicating a greater extent of particle dissolution and reprecipitation occurs. This finding would allow for further adaptability in end-user applications as it allows further control over particle characteristics. It should be noted, however, that leaving these particles in solution for a longer period of time causes them to eventually transform into solid calcite particles with a larger particle size (Figure 10).

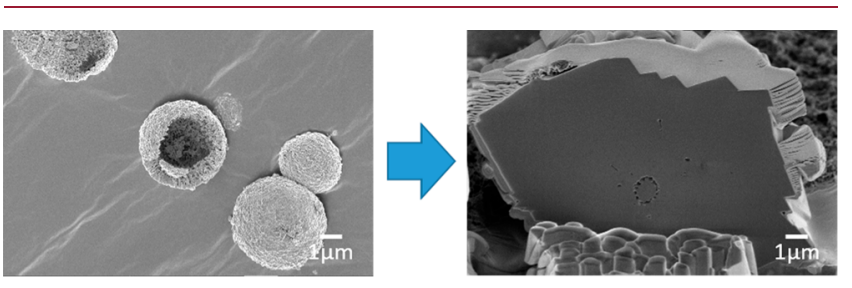

Figure 10. Transformation in structure from hollow vaterite at $\mathrm{pH} 6.6$ to cubic calcite when left overnight in solution. This transformation also leads to an increase in the particle size of the reprecipitated calcite particles.

Crossflow Approach. With a view to scaling up the production volume of precipitated calcium carbonate particles using a $\mathrm{CO}_{2}$ bubbling method, a crossflow membrane unit equipped with a ceramic membrane (pore size $=0.2 \mu \mathrm{m}$ ) was used. It is also interesting to note that this is as far as the authors are aware the first continuous system utilizing $\mathrm{CaCl}_{2}$ as a calcium source. The shear profile created by the crossflow shares similarities to that created in the stirred cell reactor. The major difference in setup was that the continuous phase was 
setup in a loop to continuously pass through the membrane until the reaction was terminated. This was done using a centrifugal pump to produce a fluid velocity of $1.75 \mathrm{~m} / \mathrm{s}$.

As can be seen from Figure 11, the particles produced are completely different in shape compared to those produced in

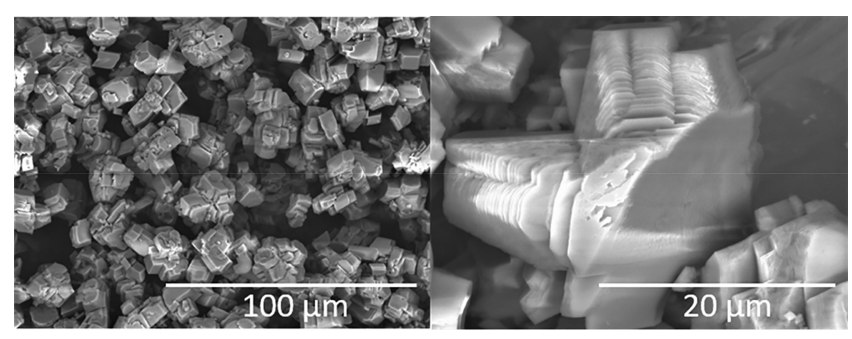

Figure 11. Precipitated laminated cubic calcite particles produced using a cross-flow membrane approach and a close up image of one such particle showing lamination in greater detail.

the cell membrane reactor (both with and without applied shear from a paddle stirrer). The particles are no longer spherical even though the same starting solution conditions were employed, they instead appear irregular and cubic in shape. A close-up of one such particle shows a layered structure of sheets that appear densely packed at one end and becoming less dense across the diameter of the particle. It is thought that a key reason for this structure is the recirculation of the continuous phase (crossflow) and its velocity. It should be noted that the crossflow velocity is much higher than that experienced in the stirred cell reactor where a bubble rising velocity is between 0.2 and $0.125 \mathrm{~m} / \mathrm{s}$. It is therefore believed that the particles produced have either (i) undergone a transformation from vaterite to laminated cubic calcite ${ }^{43}$ due to the residence time in the crossflow reactor or (ii) smaller calcite particles growing to produce the laminated cube structure as seen in Figure 11. Further work is needed to probe this in greater detail.

\section{CONCLUSIONS}

This paper explores the mechanisms behind the formation of precipitated calcium carbonate particles using $\mathrm{CO}_{2}$ gas bubbling. When probing with a stagnant $\mathrm{CO}_{2}$ bubble in solution it was found that particles precipitated both at the solution/gas interface as well as in the bulk solution. However, due to the size of the bubble and the time taken for the particles to form, these particles were found to roll down and deposit at the base of the bubble. Changing to a dynamic bubbling system, it was evident that the secondary particles produced, cannot be made via the bubble template method due to the large difference in size (i.e., between the particle and the bubble produced). Instead, the particles most likely agglomerate in the bubble wake as the bubble rises providing a site for secondary nucleation (few microns range) to occur. Another key finding is that the mean precipitate particle size was found to be independent of the membrane pore size used to produce the $\mathrm{CO}_{2}$ bubble. However, the use of a smaller pore sized membrane did alter the particle characteristics (e.g., surface porosity). The final solution $\mathrm{pH}$ (not the starting $\mathrm{pH}$ ) is also an important parameter in controlling the particle structure. At $\mathrm{pH} 8.6$ a porous vaterite particle shell with a solid core is formed, as the $\mathrm{pH}$ continues to drop from $\mathrm{pH} 8.6$ to 6.6 , slow dissolving of the surface causes the particle size to reduce while the internal structure begins to hollow out.
Allowing the $\mathrm{pH}$ to drop further causes the outer particle shell to start thickening which also allowing for control over shell thickness. Interestingly, the yield achieved was independent of the final $\mathrm{pH}$, indicating an increase in the number of particles produced as hollow particles have a much lower density than solid ones.

The particle structure can also be changed by increasing the aging time in solution, which allows for the transformation of vaterite particles into the more stable calcite with a solid core again. Interestingly, when using a recirculation system, instead of vaterite particle forming, laminated cubic structures were precipitated indicating that aging time is just as crucial as to the shear applied.

\section{ASSOCIATED CONTENT}

\section{SI Supporting Information}

The Supporting Information is available free of charge at https://pubs.acs.org/doi/10.1021/acs.cgd.0c00741.

S1. Scanning electron micrograph of the primary particles illustrating an average particle size, $d_{50}$ of 120 nm. S2. Determining bubble size using high speed imaging. S3. Calculation of enhancement factor, $E$ (PDF)

Examples of slow motion videos captured at gas flow rates of $0.1,0.5$, and $0.9 \mathrm{~L} / \mathrm{min}$ (mp4 videos) (ZIP)

\section{AUTHOR INFORMATION}

\section{Corresponding Authors}

Christopher. J. Grimes - School of Chemical and Process Engineering, Faculty of Engineering and Physical Sciences, University of Leeds, Leeds, U.K. LS2 9JT; 10 orcid.org/00000001-8261-218X; Email: pm16cg@leeds.ac.uk

Mohamed S. Manga - School of Chemical and Process Engineering, Faculty of Engineering and Physical Sciences, University of Leeds, Leeds, U.K. LS2 9JT; 이이. orcid.org/00000001-8976-4792; Email: M.S.Manga@leeds.ac.uk

\section{Authors}

Thomas Hardcastle - School of Chemical and Process Engineering, Faculty of Engineering and Physical Sciences, University of Leeds, Leeds, U.K. LS2 9JT

Tariq Mahmud - School of Chemical and Process Engineering, Faculty of Engineering and Physical Sciences, University of Leeds, Leeds, U.K. LS2 9JT; 이이이.org/0000-0002-6502$907 \mathrm{X}$

David W. York - School of Chemical and Process Engineering, Faculty of Engineering and Physical Sciences, University of Leeds, Leeds, U.K. LS2 9JT; 10 orcid.org/0000-0003-47783607

Complete contact information is available at: https://pubs.acs.org/10.1021/acs.cgd.0c00741

\section{Author Contributions}

C.J.G. is a PhD student and was primarily responsible for the collection of all data reported here and its initial analysis as well as aspects of the experimental design. C.J.G. was also the primary author of the article and responsible for various drafts. T.H. was responsible for collecting a part of the data reported and its initial analysis and also gave approval to the final version of the paper. M.S.M. contributed to the experimental design as well as data analysis. M.S.M. also contributed by reading the manuscript and suggesting revisions during its 
preparation as well as giving final approval in addition to cosupervising the study. T.M. contributed to the analysis and interpretation of the data along with critical revisions to the draft manuscript. T.M. also gave approval to the final version of the paper. D.W.Y. is group leader for the research and was responsible for the conceptual design of the experimental program. D.W.Y. also gave his approval for the final version of the paper.

\section{Notes}

The authors declare no competing financial interest.

\section{ACKNOWLEDGMENTS}

The authors would like to thank the EPSRC DTP for the scholarship EP/N509681/1 2037457 given to C.J.G. Dr. Robert Hammond and Dr. Stuart Micklethwaite are thanked for their valuable discussion, and Mr. Robert Harris is thanked for his technical assistance throughout the study.

\section{REFERENCES}

(1) Carr, F. P.; Frederick, D. K. Calcium Carbonate (updated by staff). In Kirk-Othmer Encyclopedia of Chemical Technology; John Wiley \& Sons, Inc Ed., 2014; pp 1-7.

(2) Galván-Ruiz, M.; Hernández, J.; Baños, L.; Noriega-Montes, J.; Rodríguez-García, M. E. Characterization of calcium carbonate, calcium oxide, and calcium hydroxide as starting point to the improvement of lime for their use in construction. J. Mater. Civ. Eng. 2009, 21, 694-698.

(3) Karakaş, F.; Hassas, B. V.; Celik, M. S. Effect of precipitated calcium carbonate additions on waterborne paints at different pigment volume concentrations. Prog. Org. Coat. 2015, 83, 64-70.

(4) Lux, S.; Baldauf-Sommerbauer, G.; Siebenhofer, M. Hydrogenation of inorganic metal carbonates: A review on its potential for carbon dioxide utilization and emission reduction. ChemSusChem 2018, 11, 3357-3375.

(5) Teir, S.; Auvinen, T.; Said, A.; Kotiranta, T.; Peltola, H. Performance of separation processes for precipitated calcium carbonate produced with an innovative method from steelmaking slag and carbon dioxide. Front. Energy Res. 2016, 4, 1-13.

(6) Kitamura, M.; Konno, H.; Yasui, A.; Masuoka, H. Controlling factors and mechanism of reactive crystallization of calcium carbonate polymorphs from calcium hydroxide suspensions. J. Cryst. Growth 2002, 236, 323-332.

(7) Wen, Y.; Xiang, L.; Jin, Y. Synthesis of plate-like calcium carbonate via carbonation route. Mater. Lett. 2003, 57, 2565-2571.

(8) Han, S.-J.; Yoo, M.; Kim, D.-W.; Wee, J.-H. Carbon dioxide capture using calcium hydroxide aqueous solution as the absorbent. Energy Fuels 2011, 25, 3825-3834.

(9) Teir, S.; Kotiranta, T.; Pakarinen, J.; Mattila, H.-P. Case study for production of calcium carbonate from carbon dioxide in flue gases and steelmaking slag. J. CO2 Util. 2016, 14, 37-46.

(10) Rigopoulos, S.; Jones, A. Modeling of semibatch agglomerative gas-liquid precipitation of $\mathrm{CaCO}_{3}$ in a bubble column reactor. Ind. Eng. Chem. Res. 2003, 42, 6567-6575.

(11) Hamid, S. N. S.; Jones, A. G. In Scale up of gas-liquid precipitation of calcium carbonate crystals in draft tube bubble columns. Chem. Eng. Trans., Industrial Crystall., Sorrento, Italy, 2002; pp 89-94.

(12) Rigopoulos, S.; Jones, A. In Modelling of agglomerative crystal precipitation in a gas-liquid reactor. Chem. Eng. Trans., Industrial Crystall., Sorrento, Italy, 2002; pp 161-166.

(13) Hadiko, G.; Han, Y. S.; Fuji, M.; Takahashi, M. Synthesis of hollow calcium carbonate particles by the bubble templating method. Mater. Lett. 2005, 59, 2519-2522.

(14) El-Sheikh, S.; El-Sherbiny, S.; Barhoum, A.; Deng, Y. Effects of cationic surfactant during the precipitation of calcium carbonate nano-particles on their size, morphology, and other characteristics. Colloids Surf., A 2013, 422, 44-49.
(15) Konopacka-Łyskawa, D.; Kościelska, B.; Karczewski, J.; Goląbiewska, A. The influence of ammonia and selected amines on the characteristics of calcium carbonate precipitated from calcium chloride solutions via carbonation. Mater. Chem. Phys. 2017, 193, 1318.

(16) Feng, B.; Yong, A. K.; An, H. Effect of various factors on the particle size of calcium carbonate formed in a precipitation process. Mater. Sci. Eng., A 2007, 445-446, 170-179.

(17) Popescu, M.-A.; Isopescu, R.; Matei, C.; Fagarasan, G.; Plesu, V. Thermal decomposition of calcium carbonate polymorphs precipitated in the presence of ammonia and alkylamines. Adv. Powder Technol. 2014, 25, 500-507.

(18) Tsutsumi, A.; Nieh, J. Y.; Fan, L. S. Role of the bubble wake in fine particle production of calcium carbonate in bubble column systems. Ind. Eng. Chem. Res. 1991, 30, 2328-2333.

(19) Peng, Q.; Dong, Y.; Li, Y. ZnSe semiconductor hollow microspheres. Angew. Chem., Int. Ed. 2003, 42, 3027-3030.

(20) Han, Y.; Fuji, M.; Shchukin, D.; Möhwald, H.; Takahashi, M. A new model for the synthesis of hollow particles via the bubble templating method. Cryst. Growth Des. 2009, 9, 3771-3775.

(21) Aquilano, D.; Costa, E.; Genovese, A.; Massaro, F. R.; Pastero, L.; Rubbo, M. Hollow rhombohedral calcite crystals encompassing $\mathrm{CO}_{2}$ microcavities nucleated in solution. J. Cryst. Growth 2003, 247, $516-522$.

(22) Chang, R.; Kim, S.; Lee, S.; Choi, S.; Kim, M.; Park, Y. Calcium carbonate precipitation for $\mathrm{CO}_{2}$ storage and utilization: A review of the carbonate crystallization and polymorphism. Front. Energy Res. 2017, 5, 1-12.

(23) Cheng, B.; Lei, M.; Yu, J.; Zhao, X. Preparation of monodispersed cubic calcium carbonate particles via precipitation reaction. Mater. Lett. 2004, 58, 1565-1570.

(24) Yuan, Q.; Cayre, O. J.; Manga, M.; Williams, R. A.; Biggs, S. Preparation of particle-stabilized emulsions using membrane emulsification. Soft Matter 2010, 6, 1580-1588.

(25) Bux, J.; Manga, M. S.; Hunter, T. N.; Biggs, S. Manufacture of poly(methyl methacrylate) microspheres using membrane emulsification. Philos. Trans. R. Soc., A 2016, 374, 20150134.

(26) Manga, M. S.; York, D. W. Production of concentrated Pickering emulsions with narrow size distributions using stirred cell membrane emulsification. Langmuir 2017, 33, 9050-9056.

(27) Pan, X.; York, D.; Preece, J. A.; Zhang, Z. Size and strength distributions of melamine-formaldehyde microcapsules prepared by membrane emulsification. Powder Technol. 2012, 227, 43-50.

(28) Alroaithi, M.; Sajjadi, S. Uniform polymer beads by membrane emulsification-assisted suspension polymerisation. RSC $A d v$. 2016, 6, 79745-79754.

(29) Pellegrino, J.; Schulte, L. R.; De la Cruz, J.; Stoldt, C. Membrane processes in nanoparticle production. J. Membr. Sci. 2017, $522,245-256$.

(30) Miller, D. N. Scale-up of agitated vessels gas-liquid mass transfer. AIChE J. 1974, 20, 445-453.

(31) Moo-Young, M.; Blanch, H. W. In Design of biochemical reactors mass transfer criteria for simple and complex systems; Springer: Berlin, Heidelberg, 1981; pp 1-69.

(32) Leibson, I.; Holcomb, E. G.; Cacoso, A. G.; Jacmic, J. J. Rate of flow and mechanics of bubble formation from single submerged orifices. I. Rate of flow studies. AIChE J. 1956, 2, 296-300.

(33) Bhavaraju, S. M.; Russell, T.; Blanch, H. The design of gas sparged devices for viscous liquid systems. AIChE J. 1978, 24, 454466.

(34) Hlawitschka, M. W.; Kováts, P.; Zähringer, K.; Bart, H. J. Simulation and experimental validation of reactive bubble column reactors. Chem. Eng. Sci. 2017, 170, 306-319.

(35) Tominaga, Y.; Stathopoulos, T. Turbulent Schmidt numbers for CFD analysis with various types of flowfield. Atmos. Environ. 2007, 41, 8091-8099.

(36) Liu, J.; Wang, S.; Qi, G.; Zhao, B.; Chen, C. Kinetics and mass transfer of carbon dioxide absorption into aqueous ammonia. Energy Procedia 2011, 4, 525-532. 
(37) Hu, Q.; Zhang, J.; Teng, H.; Becker, U. Growth process and crystallographic properties of ammonia-induced vaterite. Am. Mineral. 2012, 97, 1437-1445.

(38) Trushina, D. B.; Bukreeva, T. V.; Kovalchuk, M. V.; Antipina, M. N. $\mathrm{CaCO}_{3}$ vaterite microparticles for biomedical and personal care applications. Mater. Sci. Eng., C 2014, 45, 644-658.

(39) Costa, L. M. M.; Sakihama, J.; Salomão, R. Characterization of porous calcium hexaluminate ceramics produced from calcined alumina and microspheres of Vaterite $\left(\mu-\mathrm{CaCO}_{3}\right)$. J. Eur. Ceram. Soc. 2018, 38, 5208-5218.

(40) Watanabe, H.; Mizuno, Y.; Endo, T.; Wang, X.; Fuji, M.; Takahashi, M. Effect of initial $\mathrm{pH}$ on formation of hollow calcium carbonate particles by continuous $\mathrm{CO}_{2}$ gas bubbling into $\mathrm{CaCl}_{2}$ aqueous solution. Adv. Powder Technol. 2009, 20, 89-93.

(41) Kim, S.; Ko, J. W.; Park, C. B. Bio-inspired mineralization of $\mathrm{CO}_{2}$ gas to hollow $\mathrm{CaCO}_{3}$ microspheres and bone hydroxyapatite/ polymer composites. J. Mater. Chem. 2011, 21, 11070-11073.

(42) Tomioka, T.; Fuji, M.; Takahashi, M.; Takai, C.; Utsuno, M. Hollow structure formation mechanism of calcium carbonate particles synthesized by the $\mathrm{CO}_{2}$ bubbling method. Cryst. Growth Des. 2012, $12,771-776$

(43) Zhao, Y.; Li, S.; Yu, L.; Liu, Y.; Wang, X.; Jiao, J. The preparation of calcium carbonate crystals regulated by mixed cationic/ cationic surfactants. J. Cryst. Growth 2011, 324, 278-283. 